\title{
Autoimmune pancreatitis type 2
}

INSERM

\section{Source}

INSERM. (1999). Orphanet: an online rare disease and orphan drug data base.

Autoimmune pancreatitis type 2. ORPHA:280315

Type 2 autoimmune pancreatitis is a form of autoimmune pancreatitis (see this term) affecting both sexes and having a younger age of onset ( $<60$ years) and presenting with abdominal pain, steatorrhea and obstructive jaundice. 